$\mathbb{P}$ periodica polytechnica

Civil Engineering

$54 / 2(2010) 127136$

doi: 10.3311/pp.ci.2010-2.08

web: http://www.pp.bme.hu/ci

(c) Periodica Polytechnica 2010

RESEARCH ARTICLE

\section{Recommendations for new capacity values on freeways}

\author{
István Fi / János Galuska
}

Received 2009-10-27, revised 2009-12-17, accepted 2010-11-08

\begin{abstract}
By the analysis of the traffic data collected loop detectors we can get information about the capacities of different freeway sections.
\end{abstract}

The results and the analysis of the measurements able to show the real maximum traffic volume:2300-2400 pcphpl.

According to the recent regulations the maximum tolerable traffic volumes are much lower than these and lower than 2200 (capacity in $\mathrm{HCM}$ ).

We recommend using the HCM capacity values and the HCM Level of Services (LOS) categories in Hungary.

By these $20 \%$ higher capacity value are more rational from the point of view of the national economy.

\section{Keywords}

traffic data analysis · highway capacity · level of services

\section{Acknowledgement}

This work is connected to the scientific program of the "Development of quality-oriented and harmonized $R+D+I$ strategy and functional model at BME" project. This project is supported by the New Hungary Development Plan (Project ID: TÁMOP4.2.1/B-09/1/KMR-2010-0002).

Special thanks to Péter Bocz and Gabriella Devecseri for their help in the completion of measurements.

\section{István $\mathrm{Fi}$}

Department of Highway and Railway Engineering, BME, H-1111 Budapest, Múegyetem rkp. 3., Hungary

e-mail: fi@uvt.bme.hu

\section{János Galuska}

National Infrastructure Development closed Ltd, NIF Ltd, H-1134 Budapest, Váci út 45., Hungary

e-mail: janos.galuska@nif.hu

\section{Introduction}

Loop detectors are able to collect data from the traffic of the freeways. By the analysis of the data we can get information about the capacities of the freeways. These loops are able to measure the speed as well. For the measurement the best is to choose sections tend to be overloaded.

The sections were chosen according to the above mentioned criteria. One part of the data came from the pioneer system called MARABU (MAnagement of TRAffic Around BUdapest), the traffic control centre of M0 ringroad. This system is suitable for monitoring on-line the traffic flow at chosen junctions, besides saving the data in order to generate the average-speed and traffic volume relationship. Besides, three other sections were chosen, one of them from the southern Danube-bridge of M0, the others from M1 and M3 freeways. All of them are so called Raktel loop detectors. We used for the analysis the values of Table 1

\subsection{Monitored sections}

With one exception, the traffic data were collected from the whole section, that means from $2 \times 2$ lanes. The exception is the left carriageway of the M1 freeway at the M0-M1 interchange, as the loops are not working there.

Tab. 1. The chosen sections of the analysis

\begin{tabular}{ccccc}
\hline Freeway & Section & Location & Monitored lanes & System \\
\hline M0 & $15+440$ & (Danube bridge) & $2 \times 2$ & Raktel \\
\hline M0 & $\sim 0+000$ & M0-M1 jct. & $2 \times 1$ & MARABU \\
\hline M0 & $\sim 3+700$ & M0-M7 jct. & $2 \times 2$ & MARABU \\
\hline M0 & $\sim 18+500$ & M0-51101 jct. & $2 \times 2$ & MARABU \\
\hline M0 & $\sim 28+700$ & M0-M5 jct. & $2 \times 1$ & MARABU \\
\hline M1 & $\sim 15+350$ & M0-M1 jct. & 2 (right carriageway) & MARABU \\
\hline M1 & $20+290$ & (Biatorbágy) & $2 \times 2$ & Raktel \\
\hline M3 & $28+700$ & (Gödöllö) & $2 \times 2$ & Raktel \\
\hline M5 & $\sim 16+500$ & M0-M5 jct. & $2 \times 2$ & MARABU \\
\hline M7 & $\sim 15+800$ & M0-M7 jct. & $2 \times 2$ & MARABU \\
\hline
\end{tabular}




\subsection{Duration of the monitoring}

The length of the useful interval of measurement variated depending on the amount of data:

- All yearly data (2007) were available on the southern Danubebridge of M0 ringroad;

- 3 months data were available from the system 'MARABU' (September 2007, March 2008 and April 2008);

- Data were available from $1^{\text {st }}$ of January, 2007 until 6th of May, 2007 from the "Raktel" detectors on M1 and M3 motorway.

\section{The traffic-flow analysis of the Hungarian motorways and highways}

The raw data were collected into electronical files:

The data from the southern Danube-bridge was available in processed format (in MS-EXCEL format (number of vehicles without specifying classes - and their average speed)) for each hour.

In system "MARABU", every detector records in each minute the number and average speed of passenger cars and heavy vehicles (HV) then sends the data to the traffic control center. So the collected values are available together in text format. Each row of the file includes the measured values of a detector at the minute.

The 'Raktel' loops on M1 and M3 freeway collects the traffic data for an hour, but the software results pre-defined speed categories for the vehicles, instead of average speed values. The final text file includes the number of vehicles of each hour, and a classification according to speed categories. The pre-defined speed categories can be read from the header of the data files. Number of HVs are collected separately and the system calculates the average speed of them.

We processed all 3 kinds of input files with our own software, which calculated the number and average speed of cars for each hour between 5 am and 7 pm (14 hours duration, daily 14 data) in two categories: passenger cars and "non-passenger cars" (e.g. lorries, trucks). The number of measured data are shown in Table 2. These numbers are not the same in each case because there were some problems with the loops of the system "MARABU" or with the connection between them and the control centre, so data for some period were missing.

As we mentioned before, the database of the detector at M0 section 15+440 included just number of vehicles without any categories, in order to transfer the values into pc-unit, we took the data from the neighbouring junction at Szigetszentmiklós (road nr. 51101), as we had the rate of "non-passenger cars" within the entire traffic flow. But taking into consideration that data from the above mentioned junction for the whole year 2007 were not available, the rate of $\mathrm{HV}$ could not taken as an absolutely correct value, but it shows a tendency.

For transferring the hourly data to pc-unit, we took 1.5 as the pc-unit factor for "non-passenger cars" (source: HCM [1] in case of general plain site $E_{T}$ pc-unit factor for trucks and buses is 1.5 ).

It can be recognised from the analysis of the chosen year (2007, M0 Danube-bridge, shown on Figs. 12), that it is not possible for the traffic volume to exceed a maximum value. The results of the measurements can be represented with spots in a diagram. The graph turns back after reaching a certain rate of speed. In the case of the overtaking lanes of M0 ringroad, it indicates a traffic load close to the maximum possible volume, which means in this case a traffic volume of 2300-2400 pcph.

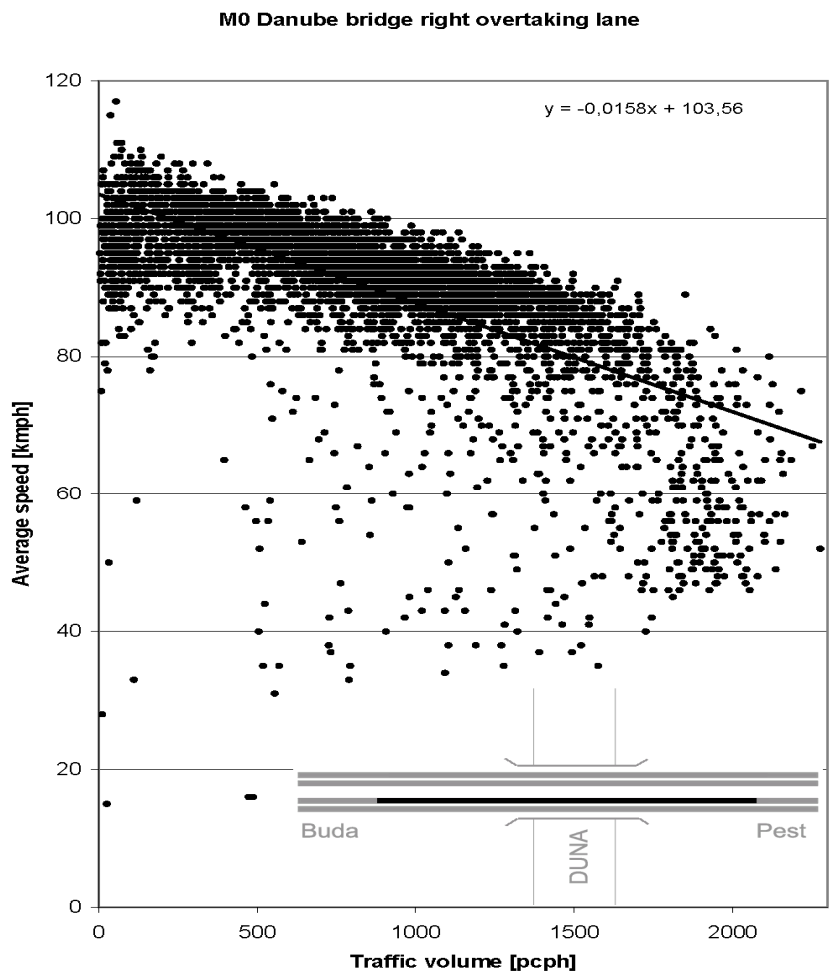

Fig. 1. The speed-traffic volume relation of the right overtaking lane of M0 ring-road

By the ongoing analysis of the database from the M0 Danubebridge, after illustrating the resulted values on Fig. 3 and Fig. 4 it became obvious, that the demanded traffic load sets around 2300-2400 pcph on the relatively narrow (3.5 metres) traffic lanes (according to HCM 2000 [1], the lane width is not dominant factor in capacity).

We adapted regression lines for the speed - traffic volume relation for the overtaking and travelling lanes of freeways. The equations are collected in Table 3 , and graphically shown on Figs. 5, 8 .

In the overtaking lanes of M0 motorway (Fig. 5) - in spite of the $80 \mathrm{~km} / \mathrm{h}$ speed limit of the section - the free-flow speed set around $100 \mathrm{~km} / \mathrm{h}$, which value decreased by the growth of the traffic volume. The highest decrease was observed in the right lane of M7 intersection. The reason of this was the impeding effect of the on-ramp traffic.

On the travelling lanes of M0 motorway (Fig. 6) the free-flow 
Tab. 2. Number of data taken for the analysis

\begin{tabular}{|c|c|c|c|c|}
\hline Motorway & Section & Lane & Number of data & $\begin{array}{c}\text { Max. traffic-volume } \\
\text { [Vehicle-unit/hour/lane] }\end{array}$ \\
\hline \multirow[t]{4}{*}{ MO } & $15+440$ & right travelling & 5045 & 2300 \\
\hline & & left travelling & 5045 & 2120 \\
\hline & & right overtaking & 5045 & 2276 \\
\hline & & left overtaking & 5045 & 2412 \\
\hline \multirow[t]{2}{*}{ MO } & $\sim 0+000$ & right travelling & 823 & 846 \\
\hline & & left travelling & 823 & 683 \\
\hline \multirow[t]{4}{*}{ MO } & $\sim 3+700$ & right travelling & 642 & 994 \\
\hline & & left travelling & 640 & 1250 \\
\hline & & right overtaking & 642 & 934 \\
\hline & & left overtaking & 640 & 849 \\
\hline \multirow[t]{4}{*}{ MO } & $\sim 18+500$ & right travelling & 905 & 1554 \\
\hline & & left travelling & 905 & 1368 \\
\hline & & right overtaking & 905 & 1923 \\
\hline & & left overtaking & 905 & 1729 \\
\hline \multirow[t]{2}{*}{ M0 } & $\sim 28+700$ & right travelling & 900 & 1804 \\
\hline & & left travelling & 900 & 1763 \\
\hline \multirow[t]{2}{*}{ M1 } & $\sim 15+350$ & right travelling & 510 & 836 \\
\hline & & right overtaking & 510 & 518 \\
\hline \multirow[t]{4}{*}{ M1 } & $20+290$ & right travelling & 1590 & 1426 \\
\hline & & left travelling & 1590 & 1340 \\
\hline & & right overtaking & 1590 & 1874 \\
\hline & & left overtaking & 1590 & 1829 \\
\hline \multirow[t]{4}{*}{ M3 } & $28+700$ & right travelling & 1764 & 1503 \\
\hline & & left travelling & 1764 & 1602 \\
\hline & & right overtaking & 1764 & 1973 \\
\hline & & left overtaking & 1764 & 2193 \\
\hline \multirow[t]{4}{*}{ M5 } & $\sim 16+500$ & right travelling & 900 & 1060 \\
\hline & & left travelling & 900 & 1602 \\
\hline & & right overtaking & 900 & 1493 \\
\hline & & left overtaking & 900 & 2031 \\
\hline \multirow[t]{4}{*}{ M7 } & $\sim 15+800$ & right travelling & 423 & 1620 \\
\hline & & left travelling & 602 & 2486 \\
\hline & & right overtaking & 423 & 2005 \\
\hline & & left overtaking & 660 & 2775 \\
\hline
\end{tabular}


Tab. 3. Values of a1 and a0 invariants for the motorway sections between interchange

\begin{tabular}{|c|c|c|c|c|}
\hline Motorway & Section & Lane & $\begin{array}{c}\text { Peak-hour } \\
\text { traffic vol. [pcph] }\end{array}$ & $\begin{array}{l}\text { Equation of the } \\
\text { regression line }\end{array}$ \\
\hline \multirow[t]{4}{*}{ MO } & $15+440$ & right travelling & 2300 & $S=-0.0059 \times F+80.1$ \\
\hline & & left travelling & 2120 & $S=-0.0075 \times F+76.7$ \\
\hline & & right overtaking & 2276 & $S=-0.0158 \times F+103.6$ \\
\hline & & left overtaking & 2412 & $S=-0.0154 \times F+97.6$ \\
\hline \multirow[t]{2}{*}{ M0 } & $\sim 0+000$ & right travelling & 846 & $S=-0.0042 \times F+79.5$ \\
\hline & & left travelling & 683 & $S=-0.0069 \times F+82.1$ \\
\hline \multirow[t]{4}{*}{ MO } & $\sim 3+700$ & right travelling & 994 & $S=0.0005 \times F+75.2$ \\
\hline & & left travelling & 1250 & $S=-0.0026 \times F+82.8$ \\
\hline & & right overtaking & 934 & $S=-0.0202 \times F+97.8$ \\
\hline & & left overtaking & 849 & $S=-0.0115 \times F+107.3$ \\
\hline \multirow[t]{4}{*}{ MO } & $\sim 18+500$ & right travelling & 1554 & $S=-0.0104 \times F+92.0$ \\
\hline & & left travelling & 1368 & $S=-0.0121 \times F+92.8$ \\
\hline & & right overtaking & 1923 & $S=-0.0099 \times F+101.2$ \\
\hline & & left overtaking & 1729 & $S=-0.0152 \times F+102.5$ \\
\hline \multirow[t]{2}{*}{ MO } & $\sim 28+700$ & right travelling & 1804 & $S=-0.0052 \times F+64.7$ \\
\hline & & left travelling & 1763 & $S=-0.0092 \times F+69.3$ \\
\hline \multirow[t]{2}{*}{ M1 } & $\sim 15+350$ & right travelling & 836 & $S=-0.0039 \times F+108.9$ \\
\hline & & right overtaking & 518 & $S=-0.0098 \times F+129.4$ \\
\hline \multirow[t]{4}{*}{ M1 } & $20+290$ & right travelling & 1426 & $S=-0.0104 \times F+109.1$ \\
\hline & & left travelling & 1340 & $S=-0.0238 \times F+120.1$ \\
\hline & & right overtaking & 1874 & $S=-0.0078 \times F+129.3$ \\
\hline & & left overtaking & 1829 & $S=-0.0133 \times F+130.6$ \\
\hline \multirow[t]{4}{*}{ M3 } & $28+700$ & right travelling & 1503 & $S=-0.0079 \times F+109.3$ \\
\hline & & left travelling & 1602 & $S=-0.0081 \times F+115.4$ \\
\hline & & right overtaking & 1973 & $S=-0.0062 \times F+131.3$ \\
\hline & & left overtaking & 2193 & $S=-0.0084 \times F+139.0$ \\
\hline \multirow[t]{4}{*}{ M5 } & $\sim 16+500$ & right travelling & 1060 & $S=-0.0069 \times F+100.4$ \\
\hline & & left travelling & 1602 & $S=-0.0108 \times F+93.9$ \\
\hline & & right overtaking & 1493 & $S=-0.0088 \times F+125.7$ \\
\hline & & left overtaking & 2031 & $S=-0.0093 \times F+115.0$ \\
\hline \multirow[t]{4}{*}{ M7 } & $\sim 15+800$ & right travelling & 1620 & $S=-0.0068 \times F+125.1$ \\
\hline & & left travelling & 2486 & $S=-0.0264 \times F+155.6$ \\
\hline & & right overtaking & 2005 & $S=-0.0066 \times F+99.2$ \\
\hline & & left overtaking & 2775 & $S=-0.0101 \times F+123.3$ \\
\hline
\end{tabular}




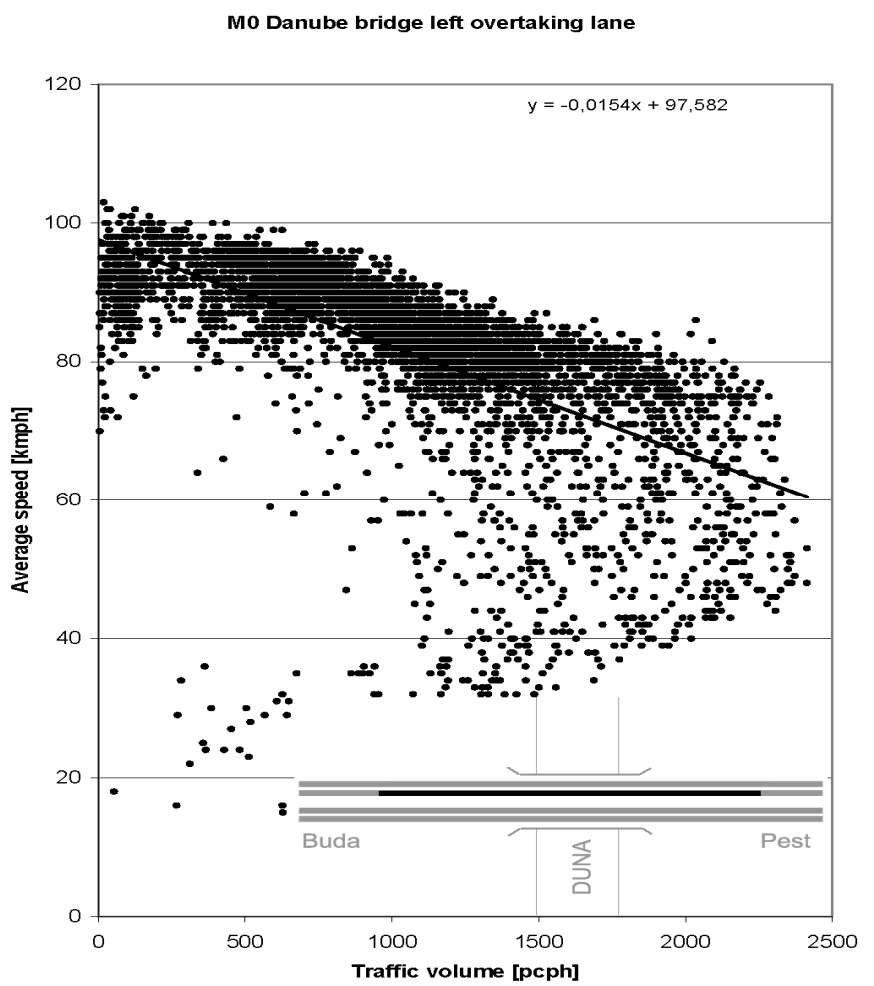

Fig. 2. The speed-traffic volume relation of the left overtaking lane of M0 ring-road

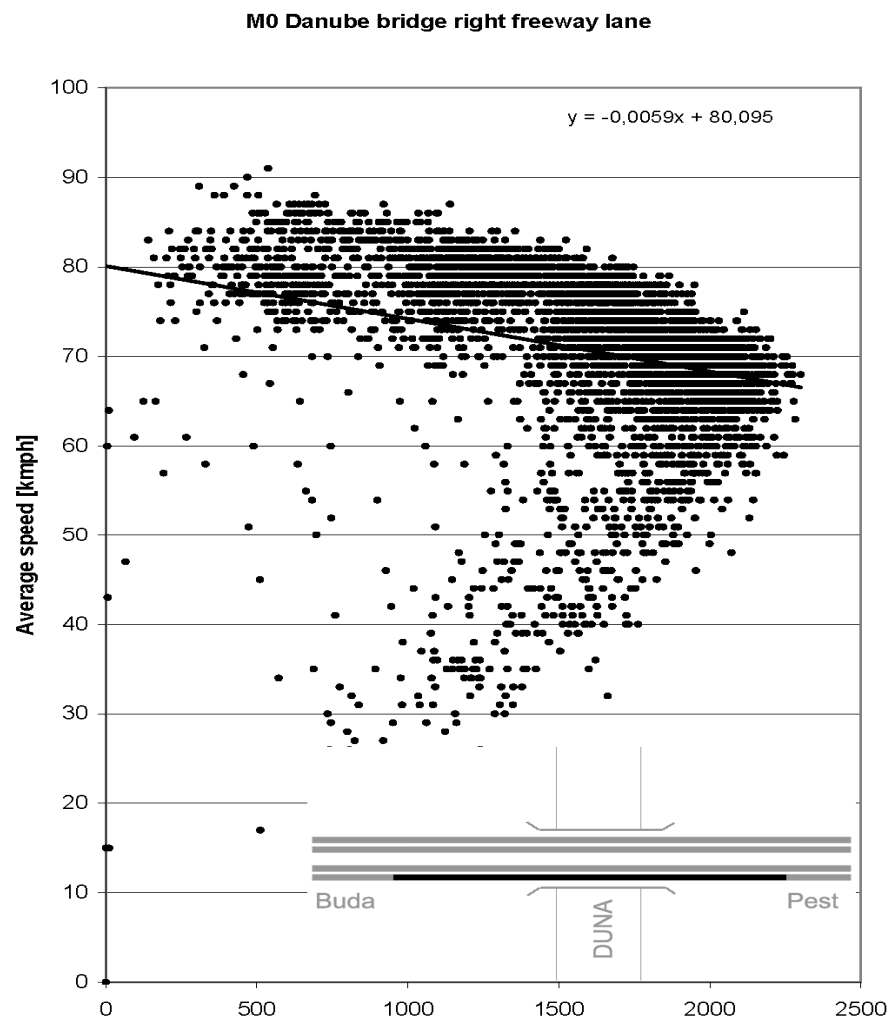

Fig. 3. The speed-traffic volume relation of the right travelling lane of M0 ring-road

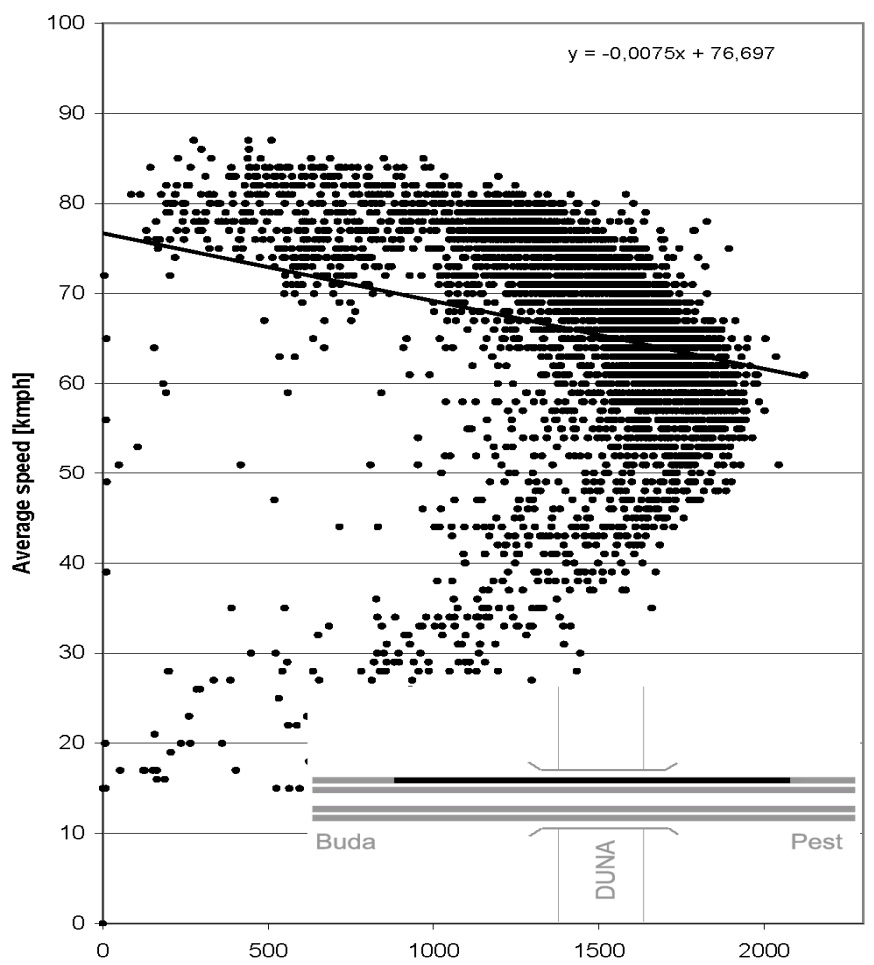

Fig. 4. The speed-traffic volume relation of the right travelling lane of M0 ring-road

speed set around $80 \mathrm{~km} / \mathrm{h}$. Here it could be also observed that the speed decreased by the volume growing, but this was less significant than in the overtaking lanes. The reason of this should be sought in the narrow lane width. In case of high traffic, with significant heavy vehicle traffic, drivers become more cautious.

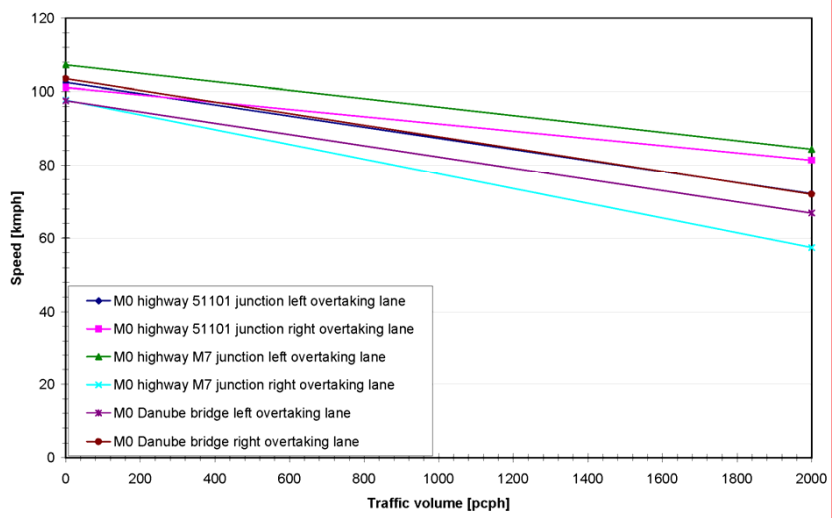

Fig. 5. Speedtraffic volume relations on the overtaking lanes of M0 motorway

In the overtaking lanes of highways (Fig. 7) the free-flow speed set around $120 \mathrm{~km} / \mathrm{h}( \pm 5 \mathrm{~km} / \mathrm{h})$. Here the speed had a linear $\sim 0.010$ decrease on all freeways. Only the left lane of M7 freeway is an exception from this, because it lays in a downgrade section so the free-flow speed could reach a high $(150 \mathrm{~km} / \mathrm{h})$ value. This value variates quite steeply by the traffic volume. In case of $2000 \mathrm{pcph}$ traffic it gets close to the speeds 


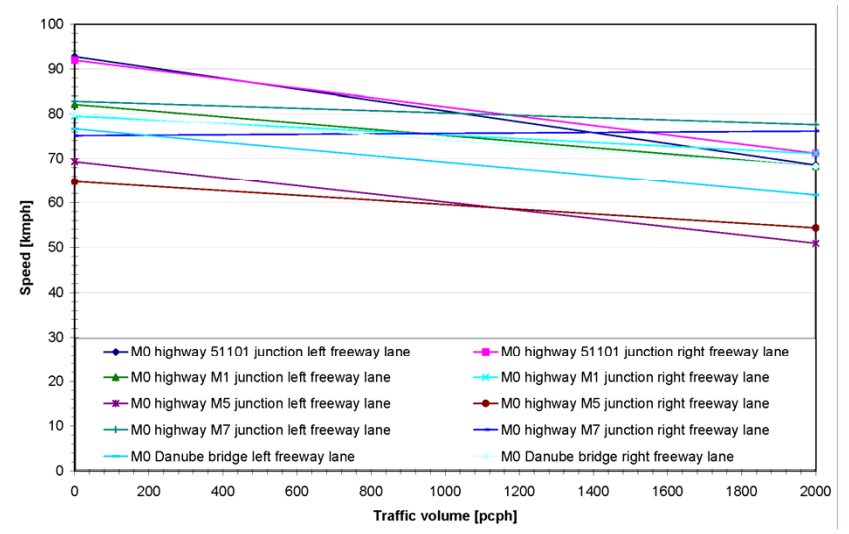

Fig. 6. Speedtraffic volume relations on the travelling lanes of M0 motorway

of other freeways.

Diagrams of the freeway lanes (Fig. 8) show $100-110 \mathrm{~km} / \mathrm{h}$ free-flow speed. The gradients of the straights variate between 0.004 - 0.010 values. Bigger difference was found only on M1 travelling lane (right lane of Biatorbágy measure point).

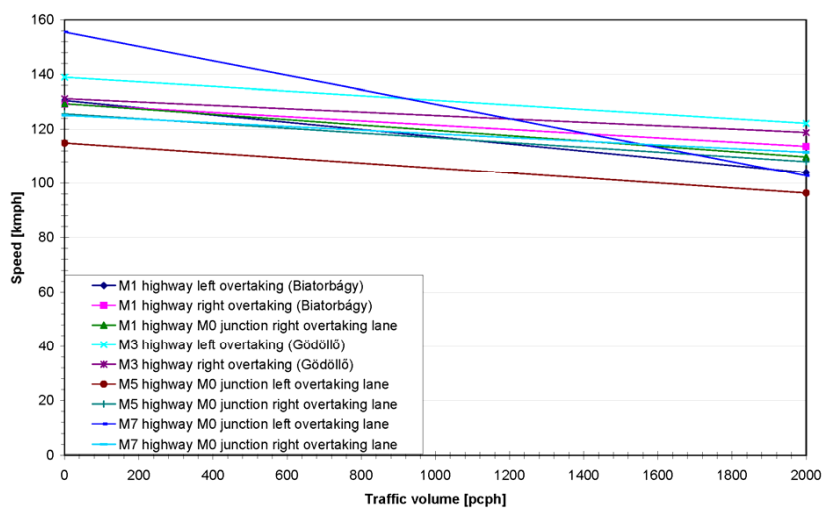

Fig. 7. Speedtraffic volume relations on the overtaking lanes of M1-M3-M5M7 highways

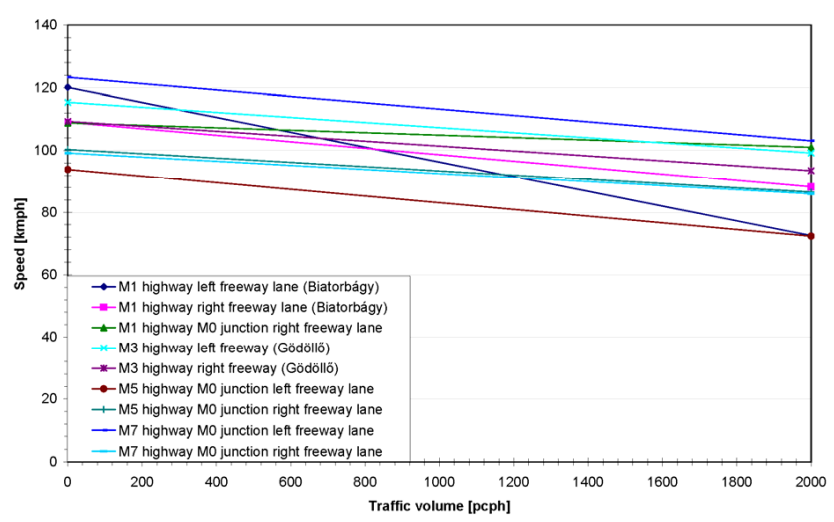

Fig. 8. Speedtraffic volume relations on the travelling lanes of M1-M3-M5M7 highways

\section{New recommendations for highways and highway in- tersection capacities}

3.1 Capacity of freeway lanes according to the Hungarian regulations

According to the previous and the recent regulations (Közutak tervezése ÚT 2-1.201:2008 [2,3]) only the tolerable, and the eligible LOS is allowed to be taken into consideration during traffic design.

Table 4 contains the allowed traffic volume values (for all types of rural highways without level crossings).

\subsection{Capacity values of HCM 2000}

The HCM [1] defines five A to $\mathbf{E}$ levels of service. Table 5 contains the densities for each LOS (A to D) for freeway sections according to HCM 2000. Densities for LOS $\mathbf{E}$ are stated in Table 6

Densities for LOS A to $\mathbf{D}$ are based on professional background. But densities of LOS $\mathbf{E}$ depends on the typical free-flow speed of the given location. By reaching the sixth level LOS F the congested traffic moves into a continuous queue or stops or it starts to waving and the values of the density varies in wide range. HCM [1] defines the relationships between LOS, flow, and speed by using the basic speed-flow curves (see Fig. 9p.

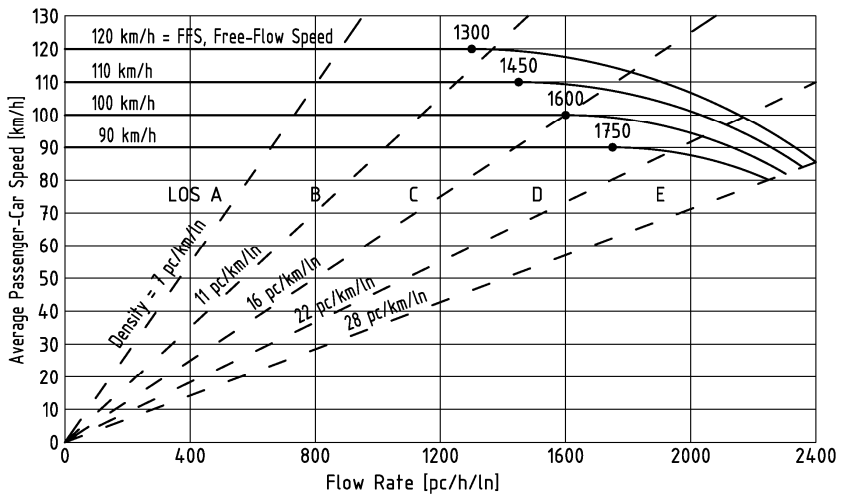

Fig. 9. Speed-flow curves with LOS criteria for highways

\subsubsection{Free-Flow Speed}

Estimation of free flow speed is based on a base free-flow speed value $(100 \mathrm{~km} / \mathrm{h}$ for highways) which is modified with different factors that have an identified effect on free-flow speed. These adjustment factors are:

- adjustment for lane width,

- adjustment for lateral clearance,

- adjustment for median type,

- adjustment for access-point densities.

The LOS criteria (the maximum density, the average speed, maximum value of $\mathrm{v} / \mathrm{c}$, and the corresponding maximum service flow rate) for different free-flow speeds are summarized in Table 7 . 
Tab. 4. Allowed capacities of freeway lanes according to ÚT 2-1.201:2008

\begin{tabular}{|c|c|c|}
\hline \multirow{2}{*}{ Rural area } & Eligible $F_{m}$ & Tolerable $F_{e}$ \\
\hline & \multicolumn{2}{|c|}{ Allowed traffic volume belonging to LOS pcph } \\
\hline Freeway (per lane) & 1200 & 1700 \\
\hline Expressway (two lanes per direction) in one direction (per lane) & 1100 & 1600 \\
\hline Multilane highway (per lane) & 1200 & 1400 \\
\hline Two lane highway (two lanes together) & 1400 & 2000 \\
\hline
\end{tabular}

Tab. 5. LOS criteria for freeway segments

\begin{tabular}{lc}
\hline LOS & Maximum density $[\mathrm{pc} / \mathrm{km} / \mathrm{ln}]$ \\
\hline A & 7 \\
\hline B & 11 \\
\hline C & 16 \\
\hline D & 22 \\
\hline
\end{tabular}

Tab. 6. LOS $\mathbf{E}$ criteria for freeway segments

\begin{tabular}{cc}
\hline Free-Flow Speed $[\mathrm{km} / \mathrm{h}]$ & Maximum density $[\mathrm{pc} / \mathrm{km} / \mathrm{ln}]$ \\
\hline 100 & 25 \\
\hline 90 & 26 \\
\hline 80 & 27 \\
\hline 70 & 28 \\
\hline
\end{tabular}

The corresponding maximum service flow rate of lanes can be calculated using the following equation:

$$
F_{\text {maxi }}=C \times(v / c)_{i}
$$

where:

- $F_{\text {maxi }}$ maximum service flow rate belonging to LOS "i" [pcphpl],

- $(v / c)_{i}$ maximum volume to capacity ratio belonging to LOS "i",

- C 2200 [pcphpl].

The capacity calculation of HCM can be used to converse the ideal flow rates to actual flow rates according to the followings:

$$
F_{i}=F_{\text {maxi }} \times w_{15} \times N \times f_{H V} \times f_{t}
$$

where:

- $F_{i}$ service flow rate belonging to LOS "i", near the actual traffic and geometry conditions, in one direction, for $\mathrm{N}$ lane [veh/h],

- $F_{\text {maxi }}$ maximum service flow rate belonging to LOS "i" $[\mathrm{pc} / \mathrm{h} / \mathrm{ln}]$,

- $w_{15}$ peak $15-\min$ period factor,
- $N$ number of lanes in one direction,

- $f_{H V}$ adjustment factor for heavy vehicles, and

- $f_{t}$ adjustment factor for tourists and strangers.

To compare the above mentioned Hungarian regulation with the American HCM two basic differences can be noticed:

- Instead of A - E LOS only two levels are used. The $F_{m}$ the design and the $F_{e}$ the so-called intervention (when the capacity can only be risen with an intervention).

- The tolerable capacity is significantly lower than 2200 the capacity of HCM recommendation.

Nevertheless it is good to see that the number of publications in the field of service level has been risen lately [4-9]. The publication of Dr. Tóth-Szabó [4], and Dr. Jankó et al. [5] should be mentioned, where they clearly commit themselves to the use of LOS A to E in the Hungarian practice. These publications have positive effect on the professional acceptation of LOS and as a result of this on the traffic safety.

\subsection{Analysis of the peak 15-min factor}

HCM methodology uses the quardrupled of peak 15-min traffic volume. To be able to compare the capacity values with each other we have made the following analysis.

For the determination of the ratio between the peak hour traffic and the quardrupled peak 15-min traffic the following method was applied:

- Based on 3 months long measurement the traffic data of the cross sections were available in each $15-\mathrm{min}$ in pcph unit.

$$
V_{15, i}
$$

- We made hourly traffic from the traffic data (the summary of the four 15-min traffics in an hour);

$$
V_{j}=\sum_{1}^{4} V_{15, i}
$$

- The maximum traffic value was chosen from the hourly traffic volumes;

$$
V_{\max }=\max \left(V_{j}\right)
$$

- We put the 15-min traffic volumes into descending order, then we chose the 50 highest 15 -min traffics; 
Tab. 7. LOS criteria for highways (HCM 2000 )

\begin{tabular}{|c|c|c|c|c|c|c|}
\hline \multirow{2}{*}{$\begin{array}{c}\text { Free-Flow Speed } \\
{[\mathrm{km} / \mathrm{h}]}\end{array}$} & \multirow{2}{*}{ Criteria } & \multicolumn{5}{|c|}{ LOS } \\
\hline & & A & $\mathrm{B}$ & $\mathrm{C}$ & $\mathrm{D}$ & $E$ \\
\hline \multirow{4}{*}{100} & Maximum density ${ }_{i}[\mathrm{pc} / \mathrm{km} / \mathrm{ln}]$ & 7 & 11 & 16 & 22 & 25 \\
\hline & Average speed $_{i}[\mathrm{~km} / \mathrm{h}]$ & 100.0 & 100.0 & 98.4 & 91.5 & 88.0 \\
\hline & Max. volume to capacity ratio ${ }_{i}(v / c)_{i}$ & 0.32 & 0.50 & 0.72 & 0.92 & 1.00 \\
\hline & Max. service flow rate ${ }_{i}, F_{\text {maxi }},[\mathrm{pc} / \mathrm{h} / \mathrm{ln}]$ & 700 & 1100 & 1575 & 2015 & 2200 \\
\hline \multirow{4}{*}{90} & Maximum density $_{i}[\mathrm{pc} / \mathrm{km} / \mathrm{ln}]$ & 7 & 11 & 16 & 22 & 26 \\
\hline & Average speed $_{i}[\mathrm{~km} / \mathrm{h}]$ & 90.0 & 90.0 & 89.8 & 84.7 & 80.8 \\
\hline & Max. volume to capacity ratio ${ }_{i}(v / c)_{i}$ & 0.30 & 0.47 & 0.68 & 0.89 & 1.00 \\
\hline & Max. service flow rate ${ }_{i}, F_{\text {maxi }},[\mathrm{pc} / \mathrm{h} / \mathrm{ln}]$ & 630 & 990 & 1435 & 1860 & 2100 \\
\hline \multirow{4}{*}{80} & Maximum density $_{i}[\mathrm{pc} / \mathrm{km} / \mathrm{ln}]$ & 7 & 11 & 16 & 22 & 27 \\
\hline & Average speed $_{i}[\mathrm{~km} / \mathrm{h}]$ & 80.0 & 80.0 & 80.0 & 77.7 & 74.1 \\
\hline & Max. volume to capacity ratio $i(v / c)_{i}$ & 0.28 & 0.44 & 0.64 & 0.85 & 1.00 \\
\hline & Max. service flow rate $i, F_{\text {maxi }},[\mathrm{pc} / \mathrm{h} / \mathrm{ln}]$ & 560 & 880 & 1280 & 1705 & 2000 \\
\hline \multirow{4}{*}{70} & Maximum density $_{i}[\mathrm{pc} / \mathrm{km} / \mathrm{ln}]$ & 7 & 11 & 16 & 22 & 28 \\
\hline & Average speed $_{i}[\mathrm{~km} / \mathrm{h}]$ & 70.0 & 70.0 & 70.0 & 69.6 & 67.9 \\
\hline & Max. volume to capacity ratio ${ }_{i}(v / c)_{i}$ & 0.26 & 0.41 & 0.59 & 0.81 & 1.00 \\
\hline & Max. service flow rate $_{i}, F_{\text {maxi }},[\mathrm{pc} / \mathrm{h} / \mathrm{ln}]$ & 490 & 770 & 1120 & 1530 & 1900 \\
\hline
\end{tabular}

- We divided the traffic of the actual hour of the 50 highest 15 min traffics with the quardrupled 15-min traffic. Finally we received 50 ratios;

- The average of the 50 ratios gave us the 15 -min factor for the busiest 50 15-minutes. The value of this:

$$
w_{15}=\frac{\sum_{1}^{50} \frac{V_{j}}{4 \times V_{15, i}}}{50}
$$

- With this ratio it became possible to compare the Hungarian and the American practices related to capacity.

- With the 15-min factor we determined in the relevant peak hour the quardrupled value of the probable highest peak 15min.

$$
V_{\max , 15}=\frac{V_{\max }}{w_{15}}
$$

Table 8 shows these factors.

It can be set out from the table that the values of the peak 15 -min factors set around 0.93 with few exceptions.

1 In both measured cross sections of M0 ringroad the low value of $w_{15}$ arises in the overtaking lanes. The reason of this could be that in case of congestion the overtaking lanes are suddenly used more frequent, so the value of $w_{15}$ follows this sudden peak with decreasing.

2 In the measured cross section of M7 highway on the right side, in both lanes the value of $w_{15}$ converges to 1 . The reason of this can be the long upgrade, wich makes the flow of the vehicles constant speed. In the opposite direction (left side), on the downgrade the value of $w_{15}$ becomes a little bit lower than 0.93 .
Generally in the above mentioned situations the $w_{15}=0.93$ value is recommended as peak 15 -min factor (as the ratio of peak hour and quardrupled peak 15 -min period). Table 9 contains the data of M0 ringroad on the southern side of Danube-bridge. We can count with the highest traffic here. Traffic data were available for each hour. We have chosen the maximum traffic of each lane. With $w_{15}$ factor this can be calculated to quardrupled peak 15 -min value.

If we take the philosophy of HCM we can say that the maximum value of the lane traffic can be set around: $2200 \times w_{15}$, that is $2200 \times 0.93 \sim 2050$. On the other hand it can be recommended to use the $2200 \mathrm{pcphpl}$ the HCM 2000 recommendation as the possible traffic volume also in Hungary. By these $20 \%$ higher capacity values the network development can be planned more rational which would also be important for the national economy.

On the third part it can be suggested in different Hungarian urban traffic analysis and modelling work, (for example publication of Schuchmann [10]) the dealing with the real peak hour factor calculating on the base of the peak 15-min factors $\left(w_{15}\right)$.

\section{Conclusions}

According to the previous and the recent regulations (Közutak tervezése ÚT 2-1.201:2008 [2], only the tolerable, and the eligible LOS is allowed to be taken into consideration during traffic design. The HCM 2000 defines five $\mathbf{A}$ to $\mathbf{E}$ levels of service. Comparing the Hungarian regulation with the American standards HCM two basic differences can be noticed. The first: Instead of A - E LOS only two levels are used. The $F_{m}$ the design and the $F_{e}$ the so called intervention (when the capacity can only be risen with an intervention).

The second: The tolerable capacity is significantly lower than 2200, the capacity of HCM recommendation. 
Tab. 8. Determination of peak 15-min factor

\begin{tabular}{|c|c|c|c|c|c|c|c|c|c|}
\hline $\begin{array}{c}\text { SIGN of } \\
\text { DETECTOR }\end{array}$ & HIGHWAY & JUNCTION & SIDE & LANE & $\begin{array}{c}\operatorname{MAX}(\mathrm{pcph})^{1} \\
V_{\max }\end{array}$ & $\begin{array}{c}15-\min \text { FACTOR }^{2} \\
w_{15}\end{array}$ & $\begin{array}{l}\operatorname{MAX}(\mathrm{pc} / 4 \times 15-\min ) \\
\text { calculated }^{3} V_{\max , 15}\end{array}$ & $\begin{array}{c}\operatorname{MAX}(\mathrm{pc} / 4 \times 15 \mathrm{~min}) \\
\text { real }^{4}\end{array}$ & $\begin{array}{l}\text { NUMBER of DATA } \\
\text { (hour) }\end{array}$ \\
\hline A & B & $\mathrm{C}$ & $\mathrm{D}$ & $\mathrm{F}$ & $\mathrm{G}$ & $\mathrm{H}$ & I & $J$ & $\mathrm{~K}$ \\
\hline DET0_3L_8 & Mo & M0-M7 & left & travelling & 1137 & 0.93 & 1232 & 1308 & 637 \\
\hline DET0_3L_9 & Mo & M0-M7 & left & overtaking & 772 & 0.85 & 941 & 944 & 638 \\
\hline DET0_3R_12 & Mo & M0-M7 & right & travelling & 904 & 0.93 & 974 & 974 & 641 \\
\hline DET0_3R_13 & Mo & M0-M7 & right & overtaking & 849 & 0.90 & 963 & 1016 & 641 \\
\hline DET0_9L_16 & Mo & Mo-Szm & left & travelling & 1244 & 0.91 & 1371 & 1356 & 903 \\
\hline DET0_9L_17 & Mo & Mo-Szm & left I & overtaking & 1572 & 0.82 & 2020 & 1798 & 904 \\
\hline DET0_9R_47 & Mo & Mo-Szm & right & travelling & 1413 & 0.94 & 1504 & 1498 & 903 \\
\hline DET0_9R_48 & Mo & Mo-Szm & right & overtaking & 1748 & 0.86 & 2074 & 1770 & 904 \\
\hline DET5_2L_32 & M5 & M0-M5 & left & overtaking & 1846 & 0.94 & 1984 & 1956 & 900 \\
\hline DET5_2L_33 & M5 & M0-M5 & left & travelling & 1457 & 0.94 & 1560 & 1606 & 900 \\
\hline DET5_2R_53 & M5 & M0-M5 & right & overtaking & 1357 & 0.92 & 1500 & 1772 & 900 \\
\hline DET5_2R_54 & M5 & M0-M5 & right & travelling & 964 & 0.92 & 1055 & 1148 & 900 \\
\hline DET7_3L_35 & M7 & M0-M7 & left & travelling & 2260 & 0.88 & 2611 & 2718 & 542 \\
\hline DET7_3L_36 & M7 & M0-M7 & left & overtaking & 2523 & 0.91 & 2803 & 2882 & 639 \\
\hline DET7_3R_39 & M7 & M0-M7 & right & travelling & 1473 & 0.98 & 1503 & 1536 & 423 \\
\hline DET7_3R_40 & M7 & M0-M7 & right & overtaking & 1823 & 0.96 & 1897 & 1938 & 417 \\
\hline
\end{tabular}

1 The maximum hourly traffic in the measured cross section (in the lane) during the measured period;

2 The average of the peak 15 -min factors of the 50 busiest peak 15-min;

3 The theoretically possible quardrupled peak 15-min traffic belonging to the maximum hourly traffic (quotient of $\mathrm{G}$ and $\mathrm{H}$ columns);

4 The quardrupled peak 15-min traffic of the given cross section (in the lane) during the measured period.

Tab. 9. Values of quardrupled peak 15 -min traffic

\begin{tabular}{cccc}
\hline Highway & Side, lane & $\begin{array}{c}\text { max. hourly } \\
\text { volume [pcph] }\end{array}$ & $\begin{array}{c}4 \times \text { max. peak } \\
\text { 15-min traffic [pcph] }\end{array}$ \\
\hline \multirow{2}{*}{ M0 } & right travelling & 2300 & 2473 \\
\cline { 2 - 4 } 15+440 & left travelling & 2120 & 2280 \\
\cline { 2 - 4 } (Danube bridge) & right overtaking & 2276 & 2447 \\
\cline { 2 - 4 } & left overtaking & 2412 & 2594 \\
\hline
\end{tabular}

On the base of our above detailed study it can be recommended to use the 2200 pcphpl as the possible traffic volume of freeway sections (as freeway lane capacity) also in Hungary. By these $20 \%$ higher capacity values the network development can be planned more rational which would also be important for the national economy.

We suggest a more detailed classification of traffic flows on the Hungarian highway network. Similarly to more European countries, five A-E levels of services of traffic demands can be recommended.

The different LOS categories have to be characterized by traffic density and traffic volume per capacity ratio. These are the parameters for Hungarian highway network which have to be worked out in the near future.

\section{References}

1 Highway Capacity Manual, Transportation Research Board National Research Council, Washington, D.C., 2000.

2 Road Planning, 1986. in Hungarian.

3 Road Planning, 2008. in Hungarian.

4 Tóth-Szabó Zs, The interpretations of the level of road service, Közúti és Mélyépítési Szemle 58, no. 7. in Hungarian.

5 Jankó $\mathrm{D}$, Tóth-Szabó Zs, Kovács F, Szénási S, The determination of the level of road service by traffic measurements' data, Közúti és Mélyépítési Szemle 58, no. 8. in Hungarian.

6 Chodur J, Capacity Models and Parameters for Unsignalised Urban Intersections in Poland, Journal of Transportation Engineering 131 (2005), no. 12, 924-930, DOI 10.1061/(ASCE)0733-947X(2005)131:12(924). http://cedb.asce.org/cgi/WWWdisplay.cgi?0530494.

7 Brilon W, Geistefeldt J, Zurlinden H, Implementing the Concept of Reliability for Highway Capacity Analysis, Transportation Research Record: Journal of the Transportation Research Board, DOI 10.3141/2027-01, (to appear in print). http://trb.metapress.com/content/u700713ur834410r/.

8 Zegeer J, Blogg M, Nguyen K, Vandehey M, Default Values for Highway Capacity and Level-of-Service Analyses, Transportation Research Record: 
Journal of the Transportation Research Board, DOI 10.3141/2071-05, (to appear in print). http://trb.metapress.com/content/jwp3q53777416281/.

9 Luttinen T, Movement Capacity at Two-Way Stop-Controlled Intersections, Transportation Research Record: Journal of the Transportation Research Board, DOI 10.3141/1883-23, (to appear in print). http://trb.metapress.com/content/572k784u46044nnl/.

10 Schuchmann G, Road network vulnerability-evaluation of measures in ranking damages and developments, Periodica Politechnica-Civil Engineering 54 (2010), no. 1, 61-65. 